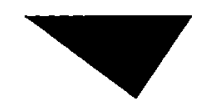

\title{
Identidades coletivas: negociando novos sentidos, politizando as diferenças
}

\author{
Rousiley C. M. Maia ${ }^{*}$ \\ Universidade Federal de Minas Gerais
}

Resumo: O interesse central deste artigo é examinar o modo pelo yual a mídia, eomno uma forma generalisada de commicação, se conecta com o projeto de identidade coletiva. seguindo a premissa pragmática búsica de gue as identidades são formadas e reprodusidas dentro de processos comunicativos e de interașono diciria. Discuto que a persyectiva encetada pelos teoricos da reflerividade confere ana renosada atençato ao papel ane os moios de commanicaşato desempenham na constituiçăo e na renovaçăo do repertónio culural de coleividades parriculares. Esta abordagem recasa tuma visão essencialista dos diferentes tipos de comminidades e comempla o) modo pelo qual as especificidades chilturais de grupos distintos se tontham instramento para a políica de idenidale. Argtmento que. ats enuregar a noção de refleviridadé preciso. contudo. dar uma êffuse mais forte a dimensano relacional e interativa da ielentidade, diante da diversidade cultural, dos problemas de valor e da mudança social, a fin de evitar an relativismo cultural radical.
Abstrat: The aim of this paper is to examine the manner throwgh which the media, as a generalised form of communication, intersects the project of collective identity following the basic pragnanic premise that identitics are formed and reproduced wihhin communicanive processes and dar 6 der interactioms. I try to evince that scholars pursuing the referivity thesis give a renested attention to the rols played by the media in the constinution and reproduction of endumal repertoire of specific collectivities. Stach a theoretical perspective aroids an essentiulist view of different lypes of commmnities and indicates the way through which cultural specifficities of certain groups become instruments for a politics of identits: In adopting the notion of reflexivity: I argue,

nonetheless, that one must give a stronger complasis to the relational and intesactive dimension of identits: in face of culntral diversity: problems of raluc and social change. in order wo aroid a radical cultural relativism.

*Doutora cm ciência política pcla University of Notingham (U.K) Professora do Departamento de Conunicação Social, UFMG 
O desenvolvimento dos meios de comunicação e das novas tecnologias pode ser visto como uma das forças mais significativas por trás da pluralização da sociedade contemporânea, motivando, em particular, a construção de identidades. É preciso, contudo, se evitar o reducionismo de tomar as transformações da construção cultural da identidade como fator derivado apenas da influência da mídia ou do uso dos meios de comunicação. Como sabemos, a urbanização, a industrialização e progressiva emigração, advindos com os processos de modernização, produziram crescente fragmentação da vida social, fazendo com que as pessoas tenham que ser muito mais ativas culturalmente para lidar com as transformações nos ambientes plurais e dinâmicos, a fim de construir um projeto coerente do 'eu', com filiações grupais múltiplas e nem sempre compatíveis entre si. Paralelamente, os processos de secularização, crescente individualização e implementação do ethos democrático, originados com a modernidade, exigem o respeito às diferenças e às diversas formas de vida, ao menos no nível normativo. Isso contribui para a pluralização das identidades e para a demanda pública de reconhecimento e proteção das diferenças.

Não há dúvida de que a mídia colabora de modo central na constituição e dinâmica de diversas identidades contemporâneas. Como bem sabemos, as pessoas podem, através dos meios de comunicação, observar o 'outro' e aprender sobre mundos espaço-temporalmente distantes, mantendo um contato vicário com quadros culturais múltiplos e distintos modos de ser. O crescente número de tecnologias de comunicação e o adensamento de redes de comunicação direta têm permitido aos indivíduos e grupos interagirem uns com os outros ou agirem dentro de quadros de quase-interação, mesmo estando situados em diferentes partes do mundo. Isto não apenas expandiu a 'percepção' da diversidade cultural em nosso entendimento diário, mas também criou um potencial para tipos diferentes de relação. Identidades distintas podem ser criadas de fragmentos, a partir de referências interculturais, de intensificação localizada de associações e de possibilidades globais.

A cultura torna-se progressivamente mediada. Refiro-me aqui à mediatização da cultura no que diz respeito aos processos através dos quais os produtos culturais mediados ganharam crescente importância como referentes culturais e contribuem, portanto, para alterar o desenvolvimento das comunidades culturais ou para criar novas comunidades (Jansson, 1999; Featherstone, 1995; Ortiz, 1994, 1997). A mídia introduz continuamente elementos para que os membros de determinadas formas de vida articulem seus referentes cultu- 
rais. Os significados dados pelos quadros de referência local têm que ser continuamente negociados com aqueles referentes mediados, isto é, com novos padrões de identificação e novos conhecimentos dados por outras comunidades que não estão presentes no contexto local compartilhado.

Em adição, a mídia moderna também modificou a dinâmica através da qual as tradições culturais reproduzem a si mesmas. É possível dizer que, nas sociedades tradicionais, as formas de socialização e reprodução da cultura estavam, em grande parte, conectadas a grupos de pessoas e a formas de autoridades peculiares, os quais encetavam compromissos específicos. Atualmente, diferentes comunidades vêm utilizando, de maneira crescente, os meios de comunicação para transmitir os materiais simbólicos, que expressam estoques culturais de conhecimento, fazendo com que as tradições locais se tornem mais e mais separadas da interação social em um ambiente físico compartilhado (Tanno e González, 1998; Gillespie, 1997; Thompson, 1995: 187). Como vem sendo reconhecido, isto cria as condições para uma renovação da tradição em uma escala sem precedentes.

\section{Identidades flexíveis, mas nem tanto e nem sempre}

A indagação sobre o modo pelo qual os processos de mediatização interferem nos quadros de referência cultural não é nova. A discussão acerca das condições sob as quais os indivíduos refletem sobre a própria natureza e o ambiente social para adquirir um senso de identidade, num mundo onde as pessoas e as mensagens se movem com maior rapidez, tem levado a visões da cultura homogeneizada ou a conclusões radicalmente relativistas da formação de identidades culturais. Como sabemos, os pensadores da teoria crítica mostraram-se particularmente sensíveis à crescente mercantilização das formas culturais. Para eles, a produção e a difusão institucionalizada de bens simbólicos pela mídia de massa deixaram os indivíduos ainda mais submissos a forças sociais e econômicals fora do seu controle, inaugurando uma nova e mais profunda forma de dominação. $\mathrm{O}$ argumento essencial é que o mundo da cultura - concebido como o mundo espiritual das idéias, da arte e dos sentimentos, reino da representação crítica da realidade e da postulação da liberdade - ao ser absorvido pela esfera da produção capitalista, passou também a fazer parte do mundo da necessidade e da reprodução material social. Uma crescente estandartização e homogeneização de diferentes padrões culturais esvazia as configurações culturais de seu potencial crítico, promovendo o planejamen- 
to do entretenimento e o 'relaxamento organizado' dos costumes, levando, enfim, a uma sociedade administrada por inteiro.

Por um lado, Adorno e Horkheimer $(1985,1990)$ alegam que os indivíduos das sociedades modernas que já sofriam os efeitos do desenraizamento da comunidade tradicional, da alienação da produção capitalista e da abstração das modernas instituições burocráticas, passaram de produtores de cultura a seus meros consumidores. Esses indivíduos acabam por ter a imaginação embotada e os mecanismos de reflexão crítica progressivamente anulados. Não há como falar da identidade nessas condições, a não ser para afirmar a perda do que poderia ser entendido como uma identidade autêntica: a memória torna-se esvaziada e a capacidade de o indivíduo produzir-se subjetivamente é sequiestrada e, com isto, as particularidades do 'eu' tornam-se mercadorias monopolizadas, socialmente condicionadas e naturalizadas. Os resíduos de individualidade diluem-se numa massa passiva. Apesar de muitos autores contemporâneos terem desafiado e se afastado das proposições mais explicitamente pessimistas dos teóricos da sociedade de massa, prevalece, para alguns, a hipótese central de Adorno de que o desenvolvimento cultural do capitalismo tardio produz estruturas de caráter tipicamente fraco, com elevada necessidade de dependência, e que tal necessidade é rotineiramente manipulada por interesses diversos, desde agitadores políticos até propagandas de consumo.

Por outro lado, certas correntes do pensamento pós-moderno tendem a enfatizar uma volatilidade crescente na constituição das identidades contemporâneas, como se fossem pastiches ou colagens. Alguns autores duvidam da existência de qualquer projeto coerente de identidade e outros defendem que a busca contemporânea para abrigo das incertezas e a insegurança ontológica levaram à formação de 'neo-tribalismos', sendo que as tribos são formadas sobretudo por imagens agregadoras, e não por corpos sociais integrados por uma diversidade de atos individuais de auto-identificação (Bauman, 1990). A coerção social e o poder estatal central, supostamente presentes nas sociedades modernas, são substituídos por atos individualizados de uma vontade particularizada (Maffesoli, 1987; Baudrillard, 1985, 1988). As ênfases nos laços sociais frágeis podem dar a impressão de que, simplesmente, escolhemos nossas identidades como se fôssemos apenas consumidores em um shopping center da cultura. A farta oferta de estilos de vida nos imbuiria, supostamente, de identidades flexíveis, facilmente remodeláveis.

Se o pertencimento a associações voluntárias e a grupos de afinidade eletiva é, sem dúvida, uma característica importante de nossa 
condição contemporânea, e se podemos transitar entre diversas comunidades com relativa facilidade, isso não é evidentemente verdade para todas as áreas da experiência. A questão é bem diferente quando lidamos com identidades relacionadas à nacionalidade, à etnia, ou ao gênero. O pertencimento a algumas dessas categorias não é fruto de nossa escolha imediata, já que nessas não podemos entrar e sair. por atos da mera vontade individual. E, quer gostemos ou não, algumas categorias nos conferem identidade através de um quadro de representações sociais mais ou menos consolidadas, independentemente de nosso ponto de vista.

Não estou aqui defendendo uma abordagem essencialista, como se as diferenças conferidas por gênero, raça, etnia, possuíssem algum conteúdo 'inerente', permanente ou objetivo. Os sentidos das diferenças são construídos social e historicamente, e estão ligados ao modo pelo qual os membros de uma certa comunidade os entendem. os especificam e os experimentam nos contextos práticos de suas vidas. A identidade de pessoas ou grupos nunca pode ser tratada de forma monolítica. Os indivíduos participam de diversos domínios sociais, compartilhando com outros algumas características sobre uma área da vida ou de interesses comuns. A "identidade" e a "identificação", sempre relacionadas ao pertencimento ao grupo, é multifacetada. Por exemplo, o grupo 'mulher' é perpassado por categorias de classe, religião, idade, etnia, etc. O grupo 'evangélicos' é diferenciado por gênero, nacionalidade, etc. Não podemos certamente definir grupos em termos de atributos essenciais que todos os membros compartilham. Os próprios indivíduos desafiam qualquer noção fixa de identidade, de modos variados e, muitas vezes, surpreendentes. Cada identidade pessoal é produto da maneira pela qual um determinado indivíduo lida com suas posições sociais que se intersecionam.

Mas isso não pode implicar em uma rejeição total da diferenciação entre grupos. Em vez de se tentar conceituar os grupos como resultado da agregação de entidades idênticas entre si, com atributos substantivos essenciais, eles devem ser definidos em termos relacionais, uns em relação a outros (Young, 1997; Calhoun, 1994). O estudo das identidades, num campo relacional, obriga a descentrar a atenção da "diferença em si" de cada grupo (como se esta pudesse ser 'apreendida' a partir somente da lógica interna das relações do grupo), para as relações que se dão nas fronteiras, no jogo de forças que organiza o campo de sua constituição simbólica. O modo pelo qual as pessoas se atribuem identificações e auto-designações está ligado a um tipo particular de consciência de si que se constitui diante 
da representação e dos interesses de outros na cena social (Monteiro, 1997:63; Somers and Gibson, 1994). E é isso, inclusive, que legitima, a partir do uso simbólico de bens culturais, num dado ambiente de oportunidades e constrangimentos, a formulação de reivindicações de direitos coletivos.

Apesar de todos os desafios para entender adequadamente o processo da identidade coletiva, o ponto que interessa destacar é que certas categorias da identidade cultural não podem ser simplesmente descartadas e a transformação de sentidos socialmente partilhados, seja no âmbito de uma dada comunidade seja no conjunto mais am-

52 plo da sociedade, exige-se a capacidade de auto-reflexão e auto-entendimento, bem como o engajamento em algum tipo de disputa e conflito sobre representações.

De mais a mais, ao contrário do pensamento pós-moderno, algumas grandes narrativas da identidade ainda possuem apelos a serem considerados. Por exemplo, a renovação nacionalista étnica na Europa mostra que reivindicações de identidade encontram-se enraizadas na especificidade cultural e que os grupos que fazem tais reivindicações pensam em si mesmos como nações. Isso envolve simultaneamente evocações de inclusão e exclusão, o delineamento de fronteiras e a busca de particularismos. Mesmo em relação à identidade nacional, que geralmente envolve uma retórica sobre a diferença cultural, há uma disputa politicamente sensível para os padrões cognitivos e valorativos, imaginados em relação aos de outras nações (Schlesinger, 1997; Anderson, 1997, 1983; Calhoun, 1994). Outro exemplo: as comunidades que gozam de uma identidade diaspórica, para as quais a condição territorial estrita não se aplica, organizam uma interpretação da própria posição na sociedade "estrangeira". Também imigrantes e exilados tendem a manter um "mapa" do funcionamento das relações da sociedade, o modo pelo qual a própria posição se relaciona com as demais (Hall, 1990; Hegde, 1998). No entanto, não é relevante buscar traçar um elenco mais detalhado de situações configurando diferentes tipos de identidade coletiva. É importante notar, por ora, que todas as construções de identidade coletiva, mesmo as mais voláteis, fazem uso de pressuposições sobre a origem do grupo social, sua evolução através do tempo e espaço e seu destino atual.

\section{Mídia e Identidades}

Sem dúvida, a mídia, como uma forma de comunicação generalizada, exerce uma grande influência em diferentes formas de vida locais, produzindo niveis crescentes de complexidade cultural. 
Como proposto acuradamente por teóricos como Anthony Giddens (1991b, 1995) Ulrich Beck (1995) e John Tompson (1995). a mídia, como uma forma generalizada de comunicação, desassociou a "capacidade de experenciar da atividade de encontrar" (Thompson, 1995: 209). As relações sociais não mais se encontram restritas às interações locais. Através dos meios de comunicação, os indivíduos podem ter acesso a "outros distantes" - lugares, valores, estilos de vida, modos de ação - e adquirir, assim, algum distanciamento dos conteúdos simbólicos das interações do face a face e das formas de autoridade que prevalecem nos ambientes da vida diária.

Os teóricos da reflexividade têm contribuído para formular o modo pelo qual a mídia, ao expandir o espaço de comunicação e aumentar o número de redes comunicativas, faz com que o processo de formação de identidade se torne mais reflexivo e aberto, no sentido de que os indivíduos têm que retornar mais e mais sobre seus próprios recursos e as formas transmitidas pela mídia, para produzir identidades coerentes para si próprios. Apesar das críticas desenvolvidas acima, não precisamos aderir à visão de que a mídia, ou a mediação da cultura, destruiu a cultura local tradicional, seguindo o conhecido legado da teoria crítica. Nem precisamos sucumbir a uma perspectiva exclusivamente deconstrutivista, tomando a mediação da cultura como um processo capaz de criar uma pura pluralidade de identidades, seguindo a suposição de que as tradições transitam livremente e que as formas simbólicas são simplesmente superpostas umas sobre as outras, como se proliferassem indefinidamente no tempo e no espaço.

A sensibilidade hermenêutica nos permite entender o modo pelo qual os indivíduos se apropriam das formas simbólicas da mídia, que podem parecer estranhas ou obscuras, sem extrair conclusões relativistas. Do ponto de vista hermenêutico, os indivíduos têm que articular a própria interpretação das formas simbólicas, uma vez que não podem alcançar uma determinação direta delas, a não ser por conceitos já intersubjetivamente compartillhados. A construção imediata de sentido dos produtos mediáticos interage com os ambientes domésticos e o contexto social local. As pessoas organizam a informação em estruturas significativas, segundo quadros de relevância compartilhados, dados pela coletividade de indivíduos com suas próprias tradições e crenças básicas. Tal perspectiva permite contemplar - tal como defendido, de forma ligeiramente distinta por Bourdieu, em sua discussão sobre habitus (1984) ou Giddens (1989) em sua teoria da 'dualidade da estrutura' -, o modo pelo qual forças estruturantes mais tradicionais (como classe, etnia, religião) podem 
ser potencialmente determinantes no que diz respeito à identidade cultural dos indivíduos. Mas o processo da produção de identidade é reflexivo e aberto, o sentimento dos próprios membros do grupo e os laços auto-identificadores precisam ser continuamente ativados e reconstruídos através de relações interativas na vida social.

A interseção dos produtos simbólicos da mídia com o projeto de identidade deve ser vista como um processo necessariamente relacional, englobando o espacial, o comunal e o discursivo. A construção de sentido que ocorre através da interpretação não é arbitrária; não é o resultado da pura vontade do interpretante. Ocorre através de 54 práticas concretas, historicamente localizadas, socialmente situadas. Assim sendo, tal perspectiva teórica deixa-nos atentos não só para a circularidade do processo interpretativo dos produtos da mídia, que se dá em lugares específicos - um processo sempre dependente do conhecimento interpretativo anterior através do qual o conhecimento do mundo pode ser adquirido e expandido - mas também para o processo da transformação social que é, através disso, possível. Para apreciar a noção de reflexividade em questão, devemos manter em mente que 'as tradições, convenções e expectativas' de uma dada cultura ou forma de vida não são entidades monolíticas. Não constituem necessariamente uma 'experiência compartilhada', pois são também construções históricas que, muito freqüentemente, excluíram importante setores de pessoas ou são arranjos que certos grupos buscam impor sobre os demais (Santos, 1998; Hobsbawn and Ranger, 1983; Alejandro, 1993). E, por isso mesmo, as tradições podem ser sempre questionadas e desafiadas de maneiras variadas e não previsíveis.

\section{Referentes culturais mediados: negociando identidades}

$O$ ponto a ser enfatizado para o desenvolvimento de meu argumento é que a mídia, por tornar as formas simbólicas disponíveis para a pública circulação e recepção, pode contribuir de modo importante para que indivíduos e coletividades produzam diferenças cognitivas dentro e entre os grupos sociais. Ela pode colaborar efetivamente para uma proliferação de identidades e um maior dinamismo cultural. No entanto, o resultado derivado de tal processo não pode ser antecipado ou previsto. Neste momento, torna-se relevante tratar, com maior especificidade, algumas definições mínimas da identidade coletiva.

O primeiro ponto que interessa destacar é que a identidade coletiva implica um certo nível de percepção consciente pelos membros de um grupo, algum grau de reflexão e alguma articulação, algum 
sentimento emocional positivo ou negativo em relação às características que os membros do grupo percebem compartilhando entre si e. assim, se diferenciando de outros grupos (Melucci, 1996a: 70-1; Somers and Gibson, 1994; Taylor, 1994). No caso da identidade coletiva, tais quadros interpretativos ou valorativos, dados pelas tradições das comunidades ou certezas básicas da vida, servem de pano de fundo ou de um conhecimento implícito para que os indivíduos produzam novos sentidos.

Tal proposição é mais específica do que o conceito de receptores dotados de uma capacidade crítica genérica. Os membros de uma comunidade, caso se sintam por alguma questão afetados em suas identidades, devem ser capazes de estabelecer uma interlocução com o material divulgado pela mídia e, se necessário, modificar a qualidade do material mediático, de modo a reorganizar a informação ou a representação, bem como mobilizar uma atividade comunicativa ao seu redor. Apropriar-se produtivamente do material mediático pressupõe uma atitude auto-reflexiva, uma capacidade de acionar experiências, histórias de vida, elementos presentes na memória coletiva, nos rituais ou nas narrativas disponíveis de uma dada comunidade para produzir novos sentidos e orientações simbólicas, que os próprios atores sejam capazes de reconhecer. Apesar da ênfase construtivista aqui em questão, isso não significa que o indivíduo possa simplesmente "inventar a si mesmo". Conforme já foi mencionado, é por que o indivíduo se encontra já sempre dentro de algum horizonte de significação que pode distinguir o que é significante daquilo que não o é.

Nesse sentido, os teóricos da reflexividade oferecem um quadro teórico útil para conferir força à autonomia do indivíduo para interpretar os bens simbólicos, reconhecendo, contudo, que existem limites à interpretação. No entanto, tal perspectiva ainda se mostra vaga para pensarmos as implicações desse processo em termos de uma renovação cultural. Não fica suficientemente claro o modo pelo qual as novas interpretações alcançadas pelos indivíduos podem se tornar material de reflexividade cultural, encetando novas visões, novos modos de percepção, atitudes e práticas, enquanto propriedades "anônimas" da cultura. Os teóricos da reflexividade direcionam nossa atenção para a potência das formas simbólicas para "revelar" o mundo às pessoas de uma maneira relativamente produtiva, ao oferecer um material diferente, talvez gratificante, para elas exercerem a reflexão e a crítica de tradições, de instituições, de práticas, isto é, da realidade social como um todo. Com efeito, as formas simbólicas podem ser recebidas e processadas individualmente, mas, para que 
interfiram no processo de identidade coletiva e, eventualmente, se transformem em material de reflexividade cultural, precisam ser de algum modo apropriadas publicamente.

Neste ponto, a pragmática formal de Habermas permite, a meu ver, uma articulação mais adequada para se combinar a ação comunicativa com a inovação cultural. Seguindo o quadro teórico habermasiano, devemos introduzir uma distinção mais clara entre o nível da articulação lingüística no pano de fundo do mundo da vida e o nível de chegar ao entendimento e ao reconhecimento mútuo entre sujeitos que agem comunicativamente, no que diz respeito à renova56 ção cultural. Tal distinção parece útil. Em primeiro lugar, para evitar que possamos retroceder a concepção dos indivíduos como 'portadores' da cultura, entendendo-os como 'receptáculos' (tal como proposto pelas filosofias do sujeito) e, assim, reintroduzir subrepticiamente a noção mesma da consciência concebida de modo solipsístico, que os teóricos da reflexividade se esforçam por rejeitar. Em segundo lugar, para conferir uma maior ênfase à perspectiva relacional da identidade, frente à diversidade cultural, aos problemas de valor e de mudança social.

Partindo de um quadro hermenêutico, como os teóricos da reflexividade, Habermas propõe:

(...) devemos entender a ação comunicativa como um elemento de um processo circular em que o ator aparece não mais como o iniciante, mas como o produto de uma tradição dentro da qual se encontra situado, do grupo de solidariedade do qual faz parte, do processo de socialização e de aprendizagem ao qual é sujeito. Apenas após este passo inicial de objetificação, a rede das ações comunicativas pode constituir-se num meio através do qual o mundo da vida se reproduz (Habermas, 1998a: 246, sic).

Apesar da 'privacidade da reflexão individual', o momento de tematização é constituído por motivos e competências dos indivíduos socializados, tanto quanto pelas tradições culturais e solidariedades de grupo. Habermas enfatiza que as pessoas, nesse sentido, permanecem ligadas internamente em suas formulações lingüísticas e expressivas com a cultura, a sociedade e seus grupos de solidariedade. Esse autor acrescenta que os novos sentidos de identidade existentes por meio da interpretação, para se manifestarem como inovações sociais e culturais, precisam ser autonomamente desenvolvidos através das interações diárias, na miríade de locais da vida social. O indivíduo, para avançar e fazer valer suas interpretações - visões diferentes, contrárias ou opostas a seus interesses, vontades ou aspirações - precisa criar uma rede de relações ativas, seja dentro de uma 
comunidade particular, seja no âmbito mais amplo da sociedade. Como lembra Habermas,

Mesmo uma renovação (...) criativa de nosso ponto de vista (...). que nos permite ver velhos problemas através de uma luz completamente diferente, não surge do nada (...). Pois um conhecimento interpretativo inovador precisa provar continuamente a sua verdade; precisa colocar os agentes numa posição para produzir sentido do que acontece com eles no mundo (Habermas, 1998b: 336-7)

Para produzir novas definições. expandir e alterar sentido, não é possível abrir mão inteiramente da habilidade de integrar elementos emergentes do presente com sentidos sociais herdados, conectar a ação a efeitos, rever narrativas em construções e reconstruçōes dinâmicas. Assim, a apropriação produtiva da identidade coletiva pressupõe não apenas que os indivíduos sejam capazes de atribuir sentidos por si mesmos, mas também de compartilhar continuamente os resultados dessas interpretações com os outros, a fim de reorganizar. de alguma forma, a sua manifestação. Deste modo, uma nova dimensão interativa, própria do reino social, é imprescindível. E, nessa dimensão, os interesses e a validade das reivindicações morais dos outros encontram-se sempre presente e o conteúdo moral da condição dos outros também é submetida à validação.

Para que as novals interpretações e pontos de vistas se dêem a conhecer e provem a sua 'relevância', os indivíduos devem invocar e conferir um significado píblico para as suas próprias interpretações de quem eles são ou gostariam de ser; quais são suas necessidades e seus desejos; qual a definição de bem viver faz sentido para eles etc... Assim sendo, o 'sentido' precisa sempre ser reconstruído dentro da intersubjetividade, através do entendimento a ser alcançado e reconhecido pelos indivíduos, pois, sem a apropriação hermenêutical e subseqüente desenvolvimento do conhecimento cultural através das pessoas nenhuma tradição pode se desenvolver ou ser mantida. Nesta medida, as pessoas alcançam algo para a cultura por meio de suas conquistas interpretativas (Habermas, 1998a:252).

Auto-conhecimento e reconhecimento: Politizando as diferenças

Chegamos, de tal forma, a uma perspectiva na qual se confere uma ênfase mais forte ao processo relacional inerente à constituição das identidades. Um ator coletivo não pode construir sua identidade independentemente de seu reconhecimento (o qual pode também significar negação ou oposição) por outros atores sociais e políticos. A identidade se constrói, em grande parte, através do problema interligado de auto-conhecimento e reconhecimento (ou não reconheci- 
mento) pelos outros (Taylor, 1994; Calhoun, 1994: 24; Mennell, 1994; Benhabib, 1996b: 83-90). Como Melucci expressa, "o paradoxo da identidade sempre consiste no fato de que a diferença, para ser afirmada e vivida como tal, pressupõe certa igualdade e certo grau de reciprocidade" (Melucci, 1996a:74).

Em outras palavras, o auto-conhecimento não pode ser completamente separado das reivindicações no sentido de ser conhecido de modo específico pelos outros. Por certo, essas duas dimensões podem não ser sempre igualmente problemáticas. Por exemplo, as tribos contemporâneas mais efêmeras e organizadas de maneira reticular, tais como as tribos de punks, de fã-clubes ou de festas raves (Gonçalves, 1997; Caiafa, 1985), não estão organizadas em torno de 'projetos' que visam às alterações sociais, nem se articulam em torno de um conjunto explícito de reivindicações, conectando meios e fins, num balanço de investimento e recompensas, no sentido político mais tradicional. Mesmo assim, essas tribos não estão imunes à tarefa de atribuir sentido a um 'nós', por mais volátil que seja. Assim, buscam se localizar dentro de um sistema de relações, tentam se reconhecer e ser reconhecidas. Os membros de tais tribos reforçam os laços uns com os outros nem sempre porque compartilham dos mesmos interesses, mas porque necessitam de tal ligação para produzir sentido às suas próprias ações. A solidariedade que une uns aos outros, o "ser junto" e o "estar junto", para utilizar os termos de Maffesoli, capacita os indivíduos a afirmarem a si mesmos como sujeitos de suas ações. Assim sendo, esses atores não deixam de estar inevitavelmente envolvidos num processo contínuo de construção e reconstrução do sentimento deles próprios através de elementos auto-identificadores, signos oferecidos pelas suas próprias práticas, experiências e 'cultura'. Esse 'sentimento deles mesmos' e a definição de 'como querem viver a própria vida' implicam uma reivindicação implícita de 'autonomia' de assim serem e, como tal, serem reconhecidos e respeitados. Se preciso, esses mesmos sentimentos podem ser ativados e, eventualmente, um poder comunicativo mobilizado para 'dar a ver' as próprias interpretações de suas identidades, ou defendê-las contra a negação ou a ofensa de outros.

Cada conflito que transgride o sistema de regras compartilhadas, independentemente se dizer respeito a recursos materiais ou simbólicos, é um conflito de identidade. Atores sociais entram em conflito para afirmar a identidade que seus oponentes lhe negam, para reapropriar de algo que lhes pertence porque são capazes de reconhecer como próprio (Melucci, 1996a: 74).

Já aqueles grupos e comunidades que compartilham de uma situ- 
ação de desvantagem, de desigualdade social, de opressão ou discriminação sistemática encontram discursos socialmente sustentados que conformam a constituição de suas identidades e vidas, com diferentes graus de agonismo e tensão. Para essas comunidades, a construção da identidade e a luta por reconhecimento se articulam, em grande medida, para desafiar os rótulos e esquemas valorativos tidos como estigmatizados; para alterar os padrões de pensamento de uma cultura majoritária, para construir novas narrativas e 'scripts' que podem ser reconhecidos, do próprio ponto de vista, como mais 'relevantes', 'positivos' ou 'corretos' (Appiah, 1994; Fraser, 1996, 1997 . Chambers, 1995, 1996). Assim sendo, a contestação de sentidos e de práticas que circulam na sociedade induz, de modo mais explícito, à elaboração mais consciente de identidade coletiva, geralmente envolvendo estratégias ativas de inclusão e exclusão e a reivindicação de direitos coletivos.

Tal nível de elaboração cognitiva não implica necessariamente um quadro unificado e coerente, como pensadores cognitivistas tendem a pensar. Em vez disso, o sentimento de identidade é construído através de interações diversas e compreende definições diferentes e, algumas vezes, contraditórias. (Young, 1997: 390; Melucci, 1996a: 71; Chambers, 1996; Baker, 1997). Autores têm reconhecido que é sobretudo em momentos de crise ou de conflito intenso, quando o grupo é submetido a pressões contraditórias, que a identidade coletiva é melhor articulada. Movimentos de oposição e antagonismo freqüentemente encorajam o cultivo da solidariedade do grupo, a fim de afirmar interesses comuns, sustentar a ruptura das relações sociais induzidas pelo conflito, organizar um conjunto coerente de reivindicações, tendo em vista mudanças na agenda da política pública. Se a existência de certos movimentos sociais organizados pode parecer como uma realidade 'dada', mais ou menos permanente, ela é sempre o resultado, em alguma medida ao menos, de uma processo ativo, não necessária e imediatamente visível.

O ponto que interessa ressaltar é que, na medida em que indivíduos ou coletividades, como atores sociais, questionam a legitimidade das normas e práticas sociais baseadas na rotina, tendem também a minar os quadros de sentidos aceitos e os projetos de identificação. Eles evidenciam, assim, a contingência de suas identidades e os atos fundadores da instituição das mesmas, o que resume numa expressão estritamente política da identidade. Como Laclau discutiu recentemente,

(...) todas as identidades políticas requerem a visibilidade de seus atos de identificação (isto é, de seus atos de instituição). Esta visibi- 
lidade é apenas obtida na medida em que formas opostas de instituição (do social) são possíveis, e esta possibilidade é revelada apenas quando aquelas formas são efetivamente postuladas e disputadas na arena política. Pois, é apenas através da relação antagonista com outros projetos que a contingência de atos particulares de instituição tornam-se aparentes, e é esta contingência que lhes conferem o caráter político. (Práticas sedimentadas não são desafiadas e, como tal, apagam o momento político de suas instituições) (Laclau, 1994: 4).

Se tal reflexão é correta, a formação de identidade e o debate político tópico sobre necessidades não devem ser entendidos como eventos inteiramente separados (Calhoun, 1998: 462; Melucci, 1996a: 68-80). O processo de construção de identidade e, conseqüentemente, a definição de interesses não devem ser relegados ao reino do privado. As identidades não são entidades prontas a informarem a atividade pública. Isso porque as identidades coletivas são parcialmente formadas no processo mesmo da comunicação e interação com os outros e não são bem definidas e nem compreensíveis, de modo racional, antes de sua articulação em práticas discursivas. Os interesses não se encontram 'dados' ou 'prontos' para serem 'liberados'. Em vez disso, eles são discursivamente construídos no momento em que os afetados se engajam em discussões, privadas e públicas, para clarear aquelas características tidas como relevantes em suas vidas, para dar expressão a anseios, sonhos e necessidades. A não articulação de valores culturais operando na sociedade apenas sustenta o status quo. Nessa perspectiva, uma dimensão 'cultural' não pode ser completamente separada de uma dimensão 'política'.

Quanto mais a "fundação" do social é colocada sob questão, menos as práticas sociais são capazes de assegurar a reprodução social, e novos atos para intervenção política e identificação fazem-se socialmente necessários. Isso leva à politização de identidades sociais, que vemos como a característica principal da vida social nas sociedades deste final do século vinte (Laclau, 1994: 4).

Dentro de tal quadro teórico, pode-se atribuir um papel crucial à mídia na construção reflexiva das identidades coletivas e na renovação cultural. Expandir a visibilidade mediática e promover relações entre culturas distantes, conjunto de práticas, sistemas de valor e formas de vida, é alargar potencialmente o modo pelo qual a formação da identidade pode se tornar mais reflexiva e de fim indefinido. Os projetos, expectativas e memórias que proporcionam a base para a identificação de uma dada comunidade podem ficar mais expostos à crítica quando os agentes que os empregam têm a chance de apren- 
der com outras tradições, adaptar-se ou partir para outras enseadas.

Os novos referentes culturais derivados dos meios de comunicilção podem proporcionar choque entre culturas, dentro e entre comunidades, sugerindo maior dinamismo e complexidade cultural. Mas se a interferência dos meios de comunicação na constituição da cultura de identidades coletivas irá levar a misturas particulares e a novas identificações; ou se irá provocar reaçóes desencadeando sincretismo e hibridismo ou, então, tentativas explicitas para descobrir particularidade. localismo e diferença devem continuar como questões empíricis. Permanece a suposição central de que as heranças culturais podem se sustentar apenas na medida em que são capazes de convencer aqueles cuja personalidade estruturam. O modo pelo qual os referentes culturais mediados se articulam nos processos de construção de identidade coletiva, condensando, em novals atitudes, modos de percepção e identidades, depende das práticals interativas concretas dos próprios sujeitos sociais.

\section{Bibliografia}

ALEJANDRO. Robert (1993) Hermenemites, Citizenship and the Public Sphere. NY: New York University Press.

ADORNO, Theodor e M. Horkheimer (1985) Dialética do Esclarecimento, Rio de Janeiro, Zahar.

ADORNO, Theodor (1990) Culture Industry reconsidered pp.27.5282 in: J. Alexander e S. Seidman (eds.) Culture and Society Contemporary Debates. Cambridge: UP

ANDERSON, Benedict (1983) Imagined Communities: Reflections on the Origins and Spread of Nationalism. London, verso.

ANDERSON, Benedict (1997) 'The origins of national consciousness' in Sreberny-Mohammadi et al. (eds) Media in Global Context. London: Arnold.

APPIAH. Anthony (1994) 'Identity. Authenticity. Survival: Multicultural Societies and Social Reproduction' pp. 149-164 in A. Gutmann (ed.) Multiculuuralism. Princeton: Princeton University Press.

BAKER, Chris (1997) 'Television and the Reflexive Project of the Self: Soaps. Teenage Talk and Hybrid Identities". British Jomrnal of Sociology: 48(4): 611-628. 
BAUMAN, Z. (1990) 'Modernity and Ambivalence', Theory Culture and Society, 7 (2-3): 239-60.

BECK, Ulrich (1995) 'A Reinvenção da Política: Rumo a uma Teoria da Modernização Reflexiva' pp. 11-71 in: Giddens, Anthony et al. Modernização Reflexiva. São Paulo: Unesp.

BENHABIB, Sheyla (ed.) (1996a) Democracy and Difference Contesting the Boundaries of the Political. Princeton: Princeton University Press.

BENHABIB, Seyla (1996b) 'The Local, the Contextual and/or Critical', Constellations, 3(1): 83-94.

BAUDRILLARD, Jean (1985) À sombra das maiorias silenciosas. São Paulo: Braisiliense.

BAUDRILLARD, Jean (1988) The Ecstasy of Communication. New York: Semiotext(e)

BOURDIEU, Pierre (1884) Distinction: A social critique of the judgment of taste. London: Routledge.

CAIAFA, Janice (1985) O Movimento Punk na Cidade: a Invasão dos Bandos Sub. Rio de Janeiro: Zahar.

CALHOUN, Craig (1994) 'Social Theory and the Politics of Identity' pp. 9-36 in C. Calhoun Social Theory and the Politics of Identity. Cambridge: Cambridge University Press.

CALHOUN, Craig (1998) 'Social Theory and the Public Sphere', in Bryan S. Turner (ed.) The Blackwell Companion to Social Theory. Oxford: Blackwell.

CANCLINI, Nestor (1996) Consumidores e Cidadãos. Rio de Janeiro: Editora UFRJ.

CASTELLS, Manuel (1997) The Power of Identity. Massachusetts: Blackwell.

CHAMBERS, Simone (1995) 'Discourse and Democratic Practices' pp. 233-259 in S. White (ed.) The Cambridge Companion to Habermas. Cambridge: Cambridge University Press.

CHAMBERS, Simone (1996) Reasonable Democracy - Jürgen Habermas and the Politics of Discourse. London: Cornell University Press. 
FEATHERSTONE, Michael (1995) Undoing Culture Globalization, Postmodernism and Identity. London: Sage.

FRASER, Nancy (1996) 'Multiculturalism and Gender Equity: the U.S. "Difference" Debates Revised', Constellations, 3 (1): 6172.

FRASER, Nancy (1997) 'Structuralism or Pragmatics? On Discourse Theory and Feminist Politics" pp. 151-170, in N. Fraser. Justice Interruptus - Critical Reflections on the "Postsocialist" Condition. London: Routledge, 1987.

FRIEDMAN, Jonathan (1994) 'Ser no mundo: globalização e localização' pp. 329-348 in: M. Featherstone (ed.) Cultura Clobal. Petrópolis: Vozes.

GIDDENS, Anthony (1989) A Constituição da Sociedade. Brasília: Martins Fontes.

GIDDENS, Anthony (1991a) As Consequências da Modernidade. São Paulo, Unesp.

GIDDENS, Anthony(1991b) Modernity and Self-identity: Stanford: Stanford University Press.

GIDDENS, Anthony et al. (1995) Modernizaz̧ço Reflexiva. São Paulo: Unesp.

GILLESPIE, Marie (1997) 'Local uses of the media: negotiating culture and identity' pp. 323 - 3.38 in Sreberny-Mohammadi, Annabelle et al. Media in Global Context, London: Amold.

GONÇALVES, Fernando N. (1997) 'Hedonismo e Ethos Contemporâneo: o fenômeno das Rave Parties', trabalho apresentado na 7 reunião anual da Compós, Rio Grande do Sul, RG.

HABERMAS, Jürgen (1994) 'Struggle for Recognition in the Democratic Constitutional State' pp. 25-74 in A. Gutmann (ed.) Multiculturalism. Princeton: Princeton University Press.

HABERMAS, Jürgen (1998a) 'Actions, Speech Acts, Linguistically mediated Interactions and the lifeworld' pp. 215-256 in M. Cooke, On the Pragmatics of Communication. Cambridge: MIT Press.

HABERMAS, Jürgen (1998b) 'Some Further Clarifications on the Concept of Communicative Rationality' pp. 307-342 in M. Cooke, On the Pragmatics of Communication. Cambridge: MIT Press. 
HALL, Stuart (1990) 'Cultural Identity and Diaspora' In: J. Rutherford (ed) Identity: community, culture, difference. London: Lawrence \& Wishart.

HEDGE, Radha S. (1998) 'Swinging the Trapeze: The negotiation of identity Among Asian Indian Immigrant Women in the United States' pp.11-33 in Tanno, D. and A. González (1998) Communication and Identity across Cultures, London: Sage.

HOBSBAWN, Eric and T. Ranger (eds.) (1983) The Invention of Tradition. Cambridge: Cambridge University Press.

64 JANSSON, André (1999) Contested Meanings: Audience Studies and the Concept of Cultural Identity. Trabalho apresentado em Crossroads in Cultural Conference, Tampere, Finland, mimeo.

KEITH, Michael and S. Pile (1993) Place and Politics of Identity. London: Routledge.

LACLAU, Ernesto (ed.) (1994) The Making of Political Identities. New York: Verso.

LASH, Scott (1995) 'A Reflexividade e seus Duplos: Estrutura, Estética e Comunidade' pp. 135-206 in A. Giddens et al., Modernização Reflexiva. São Paulo: Unesp.

LASH, Stuart and J. Friedman (eds.) (1992) Modernity and Identity. Oxford: Blackwell.

MAFFESOLI, Michel (1987) O Tempo das tribos: O Declínio do Individualismo nas Sociedades de Massa Rio de Janeiro: Forense.

MARCUS, George (1992) 'Past, Present and Emergent Identities: Requirements for Ethnographies of Late Twentieth-century Modernity World-wide' pp. 309-330 in S. Lash and J. Friedman (eds) Modernity and Identity. Oxford: Blackwell.

MELUCCI, Alberto (1996a) Challenging Codes: Collective Action in the Information Age. Cambridge: Cambridge University Press.

MELUCCI, Alberto (1996b) The Playing self. Person and Meaning in the Planetary Society. Cambridge: Cambridge University Press. 
MENNELL, Stephen (1994) 'The Formation of We-images: A Process Theory' pp. 175-197 in C. Calhoun (ed.) Social Theory and the Politics of Identity. Cambridge: Cambridge University Press.

MONTEIRO, Paula (1997) 'Globalização, identidade e diferença', Novos Estudos CEBRAP, (49): 33-46.

MORLEY, David and K. Robins (1995) Spaces of Identity: Global Media, Electronic Landscapes and Cultural Boundaries. London: Routledge.

MURDOCK, Graham (1993) 'Communications and the Constitution of Modernity', Media, Culture \& Society, 15(4): 521-540.

ORTIZ, Renato (1994) Mundialização e Cultura. São Paulo: Brasilense.

ORTIZ, Renato (1997) World Modernities and Identity, Media Development 44 (2): $37-40$

SANTOS, Myrian S. (1998) 'Sobre a autonomia da novas identidades coletivas: alguns problemas teóricos'. RBCS 38 (13): 151165.

SCHLESINGER, Philip (1997) 'Whisful thinking: cultural politics, media, and collective identities in Europe' in SrebernyMohammadi et al. (eds) (1997) Media in Global Context. London: Arnold.

SOMERS, Margaret and G. Gibson (1994) 'Reclaiming the Epistemological "Other": Narrative and the Social Construction of Identity' pp. 37-99 in C. Calhoun (ed.) Social Theory and the Politics of Identity. Cambridge: University Press.

TANNO, Dolores and A. González (1998) Communication and Identity across Cultures, London: Sage.

TAYLOR, Charles (1994) 'The Politics of Recognition' pp. 25-74 in A. Gutmann (ed.) Multiculturalism. Princeton: Princeton University Press.

THOMPSON, John P. (1995) The Media and Modernity. Cambridge: Polity Press.

TOURAINE, Alain (1994) Crítica da Modernidade. Petrópolis: Vozes. 
YOUNG, Iris M. (1996) 'Communication and the Other: Beyond Deliberative Democracy', in Seyla Benhabib (ed.) Democracy and Difference - Contesting the Boundaries of the Political. Princeton: Princeton University Press.

YOUNG, Iris M. (1997) 'Difference as resource for democratic communication' in J. Bohman and W. Rehg Deliberative Democracy. Cambridge, MIT Press.

Palavras-chave

1. identidade coletiva;

2. reflexividade;

3. inovação cultural,

4. esfera pública;

5. pragmática habermasiana 